\title{
Analysis of Writing Errors in Graduation Thesis of English Majors
}

\author{
Wei Wang \\ Changchun Sci-Tech University, Changchun, Jilin, 130600
}

Keywords: Writing Errors, English Major, Graduation Thesis

\begin{abstract}
The writing and guidance of the thesis are an important teaching practice before the graduation of English majors. Discuss and analyze three more specific problems in the writing of the thesis and discuss the methods and countermeasures to correct the mistakes and aims to promote the teachers and students to further think and improve the writing level.
\end{abstract}

\section{Introduction}

Graduation thesis is a way to judge whether students have the conditions of graduation, English professional undergraduate thesis can fully measure the English language graduates of the English language comprehensive application ability, as well as the analysis of the problem and the ability to study the problem, in a sense, The quality of the thesis is also the actual reflection of the teaching quality of English majors. In the teaching evaluation of the Ministry of Education, the thesis is an important index. Therefore, the institutions pay more attention to the thesis, and the graduation thesis is regarded as the knowledge structure of the students. Knowledge ability and ability is to solve the problem. Through the questionnaire survey, it is found that there are some general problems in the English undergraduate thesis, through the analysis of the questionnaire, to explore the causes of these problems and put forward the corresponding countermeasures.

Graduation thesis writing is an activity of college students who independently and creatively solve theoretical and practical problems on the basis of professional learning, mastery of professional knowledge, theory and skills. According to the relevant provisions of 5 colleges and universities of English higher vocational English teaching outline 6 (2000), graduation thesis writing and guidance is to cultivate students' comprehensive ability, correct attitude and scientific research methods; the second is to emphasize the sense of innovation, Encourage students to express their views. But some students think that the writing of the paper is a big copy of the article, the lack of independent thinking ability and process; at the same time due to limited knowledge of English language, English expression is not fluent, a lot of language, resulting in graduation thesis overall writing level is not high. The main problems are manifested in the language level, the way of thinking and the format specification.

\section{Analysis of Writing Errors in Graduation Thesis}

Discourse generally refers to a meaningful language, to convey complete information, logical coherence, language cohesion, with a certain communication purposes and functions of language units or communication events. Under the same subject, there are many similarities between English and Chinese discourse, but there are also great differences. American scholar Kaplan (1966) contrasts the composition of Chinese and American students. It is found that the organization and development of English discourse is the linear type, that is, the starting mode of English discourse is usually the beginning of a subject sentence, And then separately discussed, the purpose of the discussion is to start the subject sentence, and for the further development of the central idea to prepare, so the whole discourse is often connected with a clear means of convergence; and Chinese mother tongue for the use of repeated and development Spiral structure, in the subject of the circle around the first account of the details and examples, and finally sum up the conclusion; between the 
sentence composition, there is no intercourse between the English so many means of convergence. As a special form of argumentative essay, some students neglect the rules of the organization of the essay and do not consciously follow the Chinese discourse and semantics as the center, that as long as the semantic relevance, the discourse will be natural coherent, ignoring the English Habits focus on integrity and coherence of this feature. Therefore, some papers in the whole discourse is not fully equipped with the requirements of the paper, there is no suitable means between the sentence and the connection, so the whole paper can not see the meaning of the focus, logical thinking is not clear. In addition, the students of the paper composition of the paper, some materials and the subject is directly related to, and some are optional, and some ambiguous, ambiguous is not clear; some papers discussed when the theme is too general or specific, which have affected the expression of the theme. Therefore, in the process of writing the thesis, the instructor should pay special attention to standardize the students' discourse, especially the writing rules and methods of the thesis, and help the students to understand some typical Chinese-influenced discourse, so that students realize the English discourse Of the characteristics, and consciously applied to the actual writing process.

Well-known linguist Mr. Wang Li has pointed out that the structure of the sentence, the Western language is the rule of law, the Chinese language is the rule of man because English is the rule of law language, that is, pay attention to the sentence of the shape, the structure of the close. Therefore, in writing, should comply with the English language rules, if necessary, a few phrases can be combined. So the above sentence can be changed to: the on the whole such a conclusion can be drawn with a certain degree of confidence button students if be students have be assumed to have the same attitude towards the test as the others, and only if they were not punished Of the relevant knowledge

Genre is the form of communicative behavior, has its communicative function; communication purpose is to determine the important factors of genre; communication purposes and topics restricting the discourse form, content and language difficulty. Graduation thesis writing is not only to examine whether the individual language of students is standardized, whether the argument is strictly logical, but also should cultivate students' emphasis on the social normality of writing, that is, conform to certain language use strategy and discourse organization mode. The paper writing, as a kind of academic exchange and scientific research style, in the communication purpose and chapter structure has specific genre characteristics. For example, the graphic structure of English abstracts includes several parts of purpose, method, result and conclusion. Secondly, although there are common rhetorical structures in Chinese and English, there are also systematic differences. (Taylor and Chen) students in the paper writing process, often lack of genre consciousness, leading to the use of language in the language strategy. For example: students prefer to use should to make recommendations; use can, could express the possibility, and less use to express cognitive assert suggest, seem, tend to, and English papers tend to use these ambiguous verbs, making the article The conclusion is as accurate and reliable as possible, objective and euphemistic. For example: As the novel is important in English literature, we should do further discussion. The sentence is not too tactful, it is blunt, can be modified as the novel is important in English literature, further discussion might be needed. Therefore, In the process, the teacher not only pointed out to the students that the paper had its specific communicative purpose and the reader, but also should let the students pay attention to the special discourse structure and the language use characteristic.

\section{Language Level Issues}

The writing requirements of the paper are accurate and rigorous, so the words must be accurate and appropriate. Use words exactly as the use of the exact words. In order to be able to accurately express the meaning, not only to understand the literal meaning of the word, but also to understand its meaning. The accuracy of the expression of thought depends to a large extent on the accuracy of the word. For example: When introducing an American writer William Buckley Jr., William Buckley Jr., a modern American writer, the original concept is more broad, can not effectively convey the writer and other writers of the difference, the information content is small, but also Reflecting the students on the meaning of similar English vocabulary analysis. So the sentence can 
be changed to William Buckley Jr., a modern American columnist. Students who express good English will use words, such as words with abstract and general meanings, to explain attitudes, to explore relationships, and to illustrate and elaborate on general concepts and abstract concepts with specific and specific words. In order to choose a better word, in the writing can be used to distinguish between synonyms function dictionary.

By comparing English and Chinese sentences, it can be found that Chinese sentences are generally short, the structure is looser, and the semantics is expressed directly through words, and different meanings are often expressed by different phrases. English sentences are generally long, Structure is relatively close, pay attention to shape. Therefore, in English expression, should comply with the English language rules and expression habits. In writing, should avoid the expression of Chinese sentences, if necessary, can be combined into a few sentences into a long sentence. In academic writing, complex ideas often need to be organized through the corresponding language information structure, to be expressed. In English papers, the expansion of the sentence, the diversity of the means of the sentence structure and multi-layer. Therefore, the sentence in the sentence composition of more, such as a variety of juxtaposed words, phrases or clauses, so that the sentence is long and complex, sentence more cases. However, we often see too much use of simple sentences in student papers. The juxtaposition of the three sentences in Example 1 reflects, to some extent, the immaturity of the author's mind and the confusion of logic. Therefore, students in the writing process should be careful and logical thinking, sort out ideas, distinguish between primary and secondary.

In the actual writing, in addition to the above problems, the students in the paper there are overlapping structures, shortages, statements are not clear and so on. These have affected the readability of the paper, more talk about the accuracy and rigor of the text.

Choose a difficult, the size of the appropriate topic, you can ensure the smooth progress of the paper writing. Different from other professional graduation thesis, English professional thesis is written in English, it is the correct expression of language requirements. At the same time, foreign language students because of the professional language of special restrictions, with English thinking to write English papers is a certain degree of difficulty, it should narrow the scope of the topic, focus on a certain aspect of the problem. For example: in the foreign literature genre of the stream of consciousness in the novel is a relatively large problem, before writing can first narrow the scope of the study to a specific representative works, such as Wolf's Dallowov, choose this topic Not only argument angle is small, targeted, and easy to in-depth study, words of something. The topic is a high degree of generalization of the content of the paper, so that readers can quickly clear the subject of article research. When writing a title, it should be concise, strict and plain, highlight the theme. When writing the English title, we should also pay attention to the difference between Chinese and English titles: Chinese topics tend to use positive structure, the center of the word set, and the English title to first highlight the central word, and then add some modifiers. Secondly, in the writing of English headlines, the first letter of nouns, adjectives, verbs, pronouns, adverbs and participle words is capitalized, and the rest of the prepositions, articles, conjunctions, etc. Words, conjunctions at the beginning of the title, the first letter should also be capitalized.

\section{Conclusion}

Graduation thesis writing is long, many links, including the topic selection, task book, opening report, thesis writing, revision, finalization, review, reply, performance evaluation, data archiving and other links, can be described as a systematic project. Graduation thesis writing is an indispensable practice part of English professional talent training plan. It is an important part of demonstrating students 'innovation ability and an effective means to evaluate teachers' teaching quality. The author believes that cultivating students' innovative ability is the prerequisite to realize the innovation of graduation thesis writing. And the cultivation of innovative ability, the need for students, teachers, managers and the whole society together, from the foreign language education and teaching ideas to update the teaching model and teaching methods of innovation, curriculum system optimization, graduation thesis writing management, teacher and student innovation 
education The construction of the platform and so on, in order to better build English professional thesis writing innovation education system and improve the quality of graduation thesis to make unremitting efforts.

\section{Acknowledgements}

This paper is the stage research results of the research on the language error of the English majors' graduation thesis at the level of scientific research project of Changchun University of Science and Technology

\section{References}

[1] Yang Xiaorong. English major graduate thesis writing and critical thinking ability training [J]. Journal of China West Normal University, 2012 (04)

[2] Xiong Shuhui, Zou Weicheng.Study on the Development of Academic Writing Ability of English Majors in China [J]. Chinese Journal of Applied Linguistics, 2011 (03)

[3] Sheng Guoqiang, Zhou Yongmo. Analysis and countermeasures of the problems in the graduation thesis of English majors [J]. Journal of Shanghai Ocean University, 2011 (04)

[4] Ma Yue. English professional undergraduate thesis multi-dimensional writing model research [J]. Journal of Chinese Language, 2011 (03)

[5] Li Ping, Josta van Rij-Heyligers. Corpus-based academic papers Abstract genre comparative analysis [J]. Journal of Xi'an International Studies University, 2011 (01)

[6] Xu Subo. "The process of" and "genre" of the benign interaction - process genre teaching method in the "English thesis writing" teaching feasibility argument [J]. Education and Teaching Forum, 2011 (03) 